\title{
Vitamin D Level in Patients with COVID-19 and Its Relationship with Severity of The Clinical Course
}

\author{
Nearmeen M. Rashad*, Yassmin E. Abdelhamid, Neveen G. Mekhael, George E. Shaker \\ Department of Internal Medicine, Faculty of Medicine, Zagazig University, Zagazig, Egypt. \\ *Corresponding author: Nearmeen M. Rashad, Mobile: (+20) 01224248642, \\ E-mail: nrashad78@yahoo.com and n.rashad@zu.edu.eg.
}

\begin{abstract}
Background: Coronavirus disease 2019 (COVID-19) has killed millions of individuals and has led to the largest economic contraction since the Great Depression. The antiviral effects of vitamin D can hinder viral replication directly, and also be effective in an anti-inflammatory and immunomodulatory way.

Objective: This study aimed to estimate the serum levels of free 25 hydroxycholecalciferol $(25(\mathrm{OH})-\mathrm{D})$ in patients with COVID-19 infection in correlation to clinical manifestations and severity in multicenter tertiary-care hospitals, Egypt.

Subject and Methods: This cross-sectional study included 150 confirmed patients with COVID-19 by using RT-PCR for detection of the viral RNA. The COVID-19 patients were classified into four groups of mild $(n=40)$ moderate $(n=40)$, severe $(n=40)$, and critical $(n=30)$ based on disease severity. Serum concentrations of $25(\mathrm{OH})-\mathrm{D}$ were tested using enzyme-linked immunosorbent assay (ELISA).

Results According to the current study results, all included patients $(\mathrm{n}=150)$ had a low level of serum levels of 25(OH)D (11.46 \pm 4.47$)$ in COVID -19 patients compared to normal levels. Interestingly, the levels of serum 25(OH)-D were significantly low in severe $(9.5 \pm 2.71)$ and critical (6.26 \pm 2.58$)$ groups compared to mild $(16.37 \pm 2.62)$ and moderate $(12.3 \pm 2.62)$ groups. Also, there was a significant positive correlation between serum 25(OH)-D levels and hemoglobin, platelets, albumin, and $\mathrm{SPO}_{2}$ values. On the other hand, there was a significant negative correlation between serum 25(OH)-D levels and $\mathrm{LDH}, \mathrm{C}$ reactive protein, D dimer, and ferritin levels.

Conclusions: Patients with COVID-19 in particular patients with severe and critical COVID -19 had a significantly low level of serum 25(OH)-D compared to mild and moderate cases, in addition, $\mathrm{PSO} 2$ and D dimer were independently correlated with serum $25(\mathrm{OH})$-D, thus low serum $25(\mathrm{OH})$-D level could be a predictor of severe and critical COVID 19.
\end{abstract}

Keywords: COVID-19, COVID-19 in multicenter tertiary-care hospitals, Critical, Egypt, Serum 25(OH)-D.

\section{INTRODUCTION}

Mounting evidence showed that coronavirus disease 2019 (COVID-19) has rapidly spread worldwide and caused more than 1 billion infections and 2 million deaths ${ }^{(\mathbf{1})}$.

The pathophysiology of COVID-19 has not yet been fully discovered. However, the direct viral toxicity (2), endothelial cell damage and dysregulation of the immune response are widely believed to contribute to the pathogenesis of COVID-19 ${ }^{(3,4)}$. Growing evidence highlights the link of 25 hydroxycholecalciferol (25(OH)-D) and immunity. There have been tremendous advances over the last 2 decades in understanding the processes that regulate the immune system. Numerous previous studies concluded that vitamin D plays an important part in the innate antimicrobial response as it inhibits B cell proliferation and blocks B cell differentiation and immunoglobulin secretion ${ }^{(5,6)}$.

Furthermore, vitamin $\mathrm{D}$ suppresses $\mathrm{T}$ cell proliferation and results in a shift from a Th1 to a Th2 phenotype. Additionally, it affects $\mathrm{T}$ cell maturation with a skewing away from the inflammatory Th17 phenotype (7) and facilitates the induction of $\mathrm{T}$ regulatory cells ${ }^{(8)}$. These effects result in decreased production of inflammatory cytokines (IL-17, IL-21) with increased production of anti-inflammatory cytokines such as IL-10 ${ }^{(9)}$.

There is a lot of evidence that raised the antiviral effects of vitamin $\mathrm{D}$, as vitamin $\mathrm{D}$ can prevent viral replication directly, and also be effective in an antiinflammatory and immunomodulatory way ${ }^{\left({ }^{10}\right)}$. It seems that SARS-CoV-2 primarily uses the immune evasion process during infection, which is followed by hyper reaction and cytokine storm in some patients ${ }^{(11)}$, as a known pathogenic process of acute respiratory disease syndrome (ARDS) development ${ }^{(\mathbf{1 2})}$.

SARS-CoV-2 uses angiotensin-converting enzyme 2 as the host receptor to enter into alveolar and intestinal epithelial cells ${ }^{(13)}$. Subsequent dysregulation of the renin-angiotensin system may lead to excess cytokine production resulting in prospective fatal ARDS (14).

The SARS-CoV-2 infection has killed millions of individuals and has led to the largest economic contraction since the Great Depression. Therefore, therapies are required to treat severe COVID-19 and to prevent its complications. Thus, the present study aimed to estimate the serum levels of free 25 hydroxycholecalciferol $(25(\mathrm{OH})-\mathrm{D})$ in patients with COVID-19 infection in correlation to clinical 
manifestations and severity in multicenter tertiary-care hospitals, Egypt during the period from August 2020 to May 2021.

\section{SUBJECTS AND METHODS}

This cross-sectional study included 150 patients conducted from multicenter tertiary-care hospitals; Zagazig University Hospitals, Sharqia Governorate and Temay Alamdid Hospital, Dakahlia Governorate, Egypt, from August 2020 to May 2021.

150 Patients with a confirmed diagnosis of COVID-19 based on laboratory (PCR) were stratified into four groups; mild $(n=40)$ moderate $(n=40)$, severe $(n=40)$, and critical $(n=30)$ according to COVID-19 severity as reported by WHO and Egyptian Ministry of Health and Population (MOH) definitions ${ }^{(14)}$.

Clinical, demographic, laboratory and radiological data were obtained at initial admission to the hospital. Pediatric and pregnant patients, and patients with a history of other infections were excluded.

\section{Ethical considerations:}

Informed written consent was obtained from each eligible patient who participated in the study. The current study was approved by the Faculty of Medicine, Zagazig University (approval code: IRB 6387-9-2-2-2020). This work has been carried out in accordance with The Code of Ethics of the World Medical Association (Declaration of Helsinki) for studies involving humans.

\section{Blood sampling:}

Blood samples were drawn from all patients after an overnight fast. Sera were separated after $1 \mathrm{~h}$ longstanding and stored at $-80^{\circ} \mathrm{C}$.

\section{Determination of serum vitamin $D$ levels:}

Serum concentrations of $25(\mathrm{OH})-\mathrm{D}$ were tested using enzyme-linked immunosorbent assay, (Cat No. EQ 6411- 9601, Euroimmun Medizinische Labordiagnostika AG, Germany). Current recommendations define vitamin $\mathrm{D}(\mathrm{VD})$ deficiency as serum 25(OH)-D levels less than $20 \mathrm{ng} / \mathrm{ml}$ and VD insufficiency less than $30 \mathrm{ng} / \mathrm{ml}^{(15)}$.

\section{Statistical analysis}

Data analyses were done with a statistical package for the social sciences software (SPSS Version 21, Chicago, Illinois). Quantitative data were expressed as mean \pm standard deviation (SD), while qualitative data were expressed as number and percentage. The relationships of serum $25(\mathrm{OH})-\mathrm{D}$ levels with clinical and laboratory parameters among COVID -19 patients were tested with the Pearson correlation. A stepwise multiple linear regression analysis was done to detect the main predictors of serum 25(OH)-D levels in the COVID-19 patients.

Receiver operating characteristic (ROC) analysis was performed to assess the diagnostic power of serum 25(OH)-D levels. We considered $\mathrm{P}$ to be significant at $<0.05$ with a $95 \%$ confidence interval (CI).

\section{RESULTS}

Demographic and clinical characteristics in COVID-19 patients $(n=150)$ at admission as well as comorbidities are shown in table 1.

Table (1): Demographic and clinical characteristics in COVID-19 patients

\begin{tabular}{|l|c|}
\hline Characteristics, symptoms & $\begin{array}{c}\text { COVID-19 patients } \\
\text { (N=150) }\end{array}$ \\
\hline Age (years), (mean \pm SD) & $51.21 \pm 13.14$ \\
\hline Sex & $74(49.3 \%)$ \\
Male, $\mathrm{n}(\%)$ & $86(50.7 \%)$ \\
Female, $\mathrm{n}(\%)$ & $32.6 \pm 6.91$ \\
\hline BMI, kg/m ${ }^{2}$ (mean \pm SD) & 27 \\
\hline Current smoker & \\
\hline Coexisting condition & 16 \\
\hline No & 45 \\
\hline Hypertension & 48 \\
\hline Diabetes & 17 \\
\hline Chronic liver disease & 10 \\
\hline Malignancy & 17 \\
\hline Chronic obstructive & \\
pulmonary disease & 13 \\
\hline Immunosuppression & \\
\hline Symptoms & 135 \\
\hline Fever & 54 \\
\hline Cough & 45 \\
\hline Sputum production & 9 \\
\hline Hemoptysis & 104 \\
\hline Dyspnea & 31 \\
\hline Nasal congestion & 34 \\
\hline Sore throat & 74 \\
\hline Myalgia & 47 \\
\hline Anosmia & 33 \\
\hline Abdominal pain & 61 \\
\hline Fatigue & 68 \\
\hline Diarrhea & 31 \\
\hline Nausea and vomiting & \\
\hline Headache & \\
\hline & \\
\hline & \\
\hline
\end{tabular}

As regard laboratory parameters; there were elevations of liver enzymes (ALT and AST) and an increase of inflammatory and coagulopathy markers including LDH, C-reactive protein-dimer, ferritin. On the other hand, patients with COVID-19 had anemia, thrombocytopenia, and hypoalbuminemia as well as low $\mathrm{SPO}_{2}$ (Table 2). 
Table (2): Laboratory findings of patients with COVID-19 on admission

\begin{tabular}{|l|c|}
\hline \multicolumn{1}{|c|}{ Characteristics } & $\begin{array}{c}\text { COVID-19 patients } \\
(\mathbf{N}=150)(\text { Mean } \pm \text { SD })\end{array}$ \\
\hline Leukocytes, $\times 10^{9} / \mathrm{L}$ & $9.5 \pm 2.691$ \\
\hline Neutrophils, $\times 10^{9} / \mathrm{L}$ & $6.81 \pm 1.98$ \\
\hline Lymphocytes $\times 10^{9} / \mathrm{L}$ & $1.4 \pm 0.68$ \\
\hline Platelets, $\times 10^{9} / \mathrm{L}$ & $219.3 \pm 9.52$ \\
\hline Hemoglobin, $\mathrm{g} / \mathrm{L}$ & $10.01 \pm 1.491$ \\
\hline International normalized ratio & $1.16 \pm 0.173$ \\
\hline Albumin, $\mathrm{g} / \mathrm{L}$ & $2.520 \pm 0.98$ \\
\hline Alanine aminotransferase, U/L & $37.1 \pm 8.29$ \\
\hline Aspartate aminotransferase, U/L & $35.1 \pm 1.56$ \\
\hline Total bilirubin, mmol/L & $0.96 \pm 0.049$ \\
\hline Potassium, mmol/L & $4.01 \pm 0.57$ \\
\hline Sodium, mmol/L & $135.02 \pm 6.74$ \\
\hline Blood urea nitrogen, $\mathrm{mmol} / \mathrm{L}$ & $33.17 \pm 5.81$ \\
\hline Creatinine, $\mathrm{mmol} / \mathrm{L}$ & $0.92 \pm 0.04$ \\
\hline Lactate dehydrogenase, $\mathrm{U} / \mathrm{L}$ & $239.3 \pm 13.7$ \\
\hline C-reactive $\mathrm{protein}, \mathrm{mg} / \mathrm{L}$ & $37.92 \pm 4.7$ \\
\hline D-dimer $(\mathrm{ng} / \mathrm{mL})$ & $4.7 \pm 1.07$ \\
\hline Ferritin $(\mathrm{ng} / \mathrm{mL})$ & $432.1 \pm 17.1$ \\
\hline Serum $25(\mathrm{OH})-\mathrm{D}(\mathrm{ng} / \mathrm{ml})$ & $11.46 \pm 2.47$ \\
\hline Pulse oxygen saturation & $73.8 \pm 3.19$ \\
\hline
\end{tabular}

Radiographic findings of patients with COVID-19 on admission are shown in table 3.

Table (3): Radiographic findings of patients with COVID-19 on admission

\begin{tabular}{|l|c|}
\hline \multicolumn{1}{|c|}{ Chest x-ray/CT findings } & $\begin{array}{c}\text { COVID-19 } \\
\text { patients } \\
\text { (N=150) }\end{array}$ \\
\hline Normal & 42 \\
\hline Unilateral pneumonia & 30 \\
\hline Bilateral pneumonia & 30 \\
\hline $\begin{array}{l}\text { Multiple mottling and ground- } \\
\text { glass opacity }\end{array}$ & 48 \\
\hline
\end{tabular}

Our results showed that lower values of serum 25(OH)-D (11.46 \pm 4.47$)$ in COVID -19 patients (Table $1)$.

COVID -19 patients stratified into four groups according to severity; the levels of serum $25(\mathrm{OH})$-D were significantly low in severe $(9.5 \pm 2.71)$ and critical (6.26 \pm 2.58$)$ groups compared to mild $(16.37 \pm 2.62)$ and moderate (12.3 \pm 2.62$)$ groups (Fig. 1).

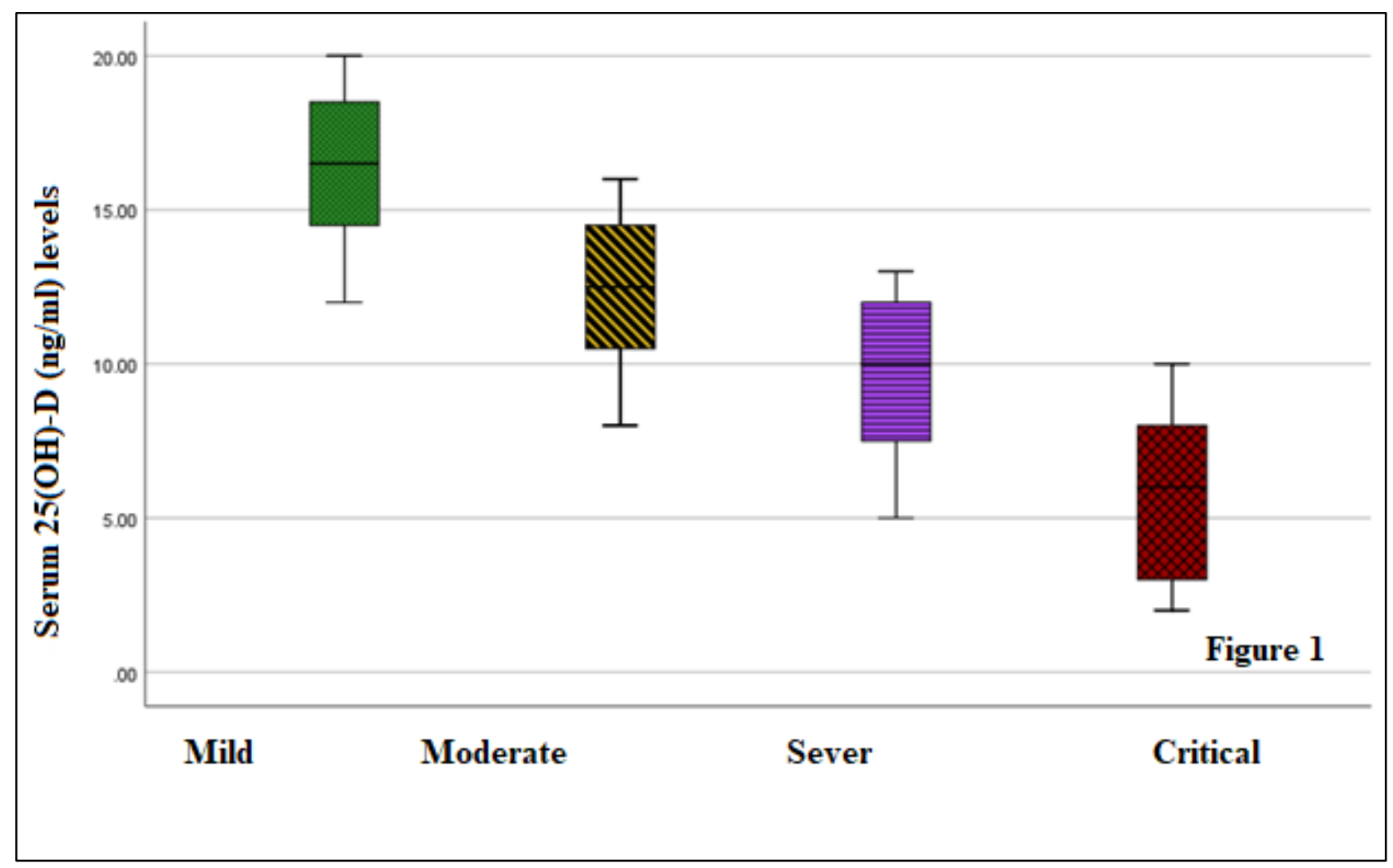

Figure (1): Serum 25(OH)-D (ng/ml) levels in COVID-19 patients stratified according to severity

Our results demonstrated a significant positive correlation between serum 25(OH)-D levels and hemoglobin, platelets, albumin, and $\mathrm{SPO}_{2}$ values. Interestingly, our results demonstrated a significant negative correlation between serum 25(OH)-D levels and lactate dehydrogenase (LDH), C-reactive protein, D dimer, and ferritin levels (Tables 4). 
Table (4): Pearson correlations of serum 25(OH)-D (ng/ml) levels with clinical and laboratory characteristics of COVID -19 patients

\begin{tabular}{|l|c|c|}
\hline \multirow{2}{*}{\multicolumn{1}{|c|}{ Characteristics }} & \multicolumn{2}{c|}{ COVID -19 patients } \\
\cline { 2 - 3 } & $\mathbf{r}$ & $\mathbf{P}$ \\
\hline Leukocytes, $\times 10^{9} / \mathrm{L}$ & -0.055 & 0.507 \\
\hline Neutrophils, $\times 10^{9} / \mathrm{L}$ & -0.046 & 0.574 \\
\hline Lymphocytes $\times 10^{9} / \mathrm{L}$ & 0.126 & 0.123 \\
\hline Platelets, $\times 10^{9} / \mathrm{L}$ & 0.519 & $<0.001$ \\
\hline Hemoglobin, $\mathrm{g} / \mathrm{L}$ & 0.831 & $<0.001$ \\
\hline International normalized ratio & -0.006 & 0.944 \\
\hline Albumin, g/L & 0.126 & 0.123 \\
\hline Alanine aminotransferase, $\mathrm{U} / \mathrm{L}$ & 0.042 & 0.612 \\
\hline Aspartate aminotransferase, $\mathrm{U} / \mathrm{L}$ & 0.027 & 0.743 \\
\hline Total bilirubin, mmol/L & 0.054 & 0.510 \\
\hline Potassium, mmol/L & 0.056 & 0.498 \\
\hline Sodium, $\mathrm{mmol} / \mathrm{L}$ & -0.028 & 0.738 \\
\hline Blood urea nitrogen, $\mathrm{mmol} / \mathrm{L}$ & -0.081 & 0.326 \\
\hline Creatinine, $\mathrm{mmol} / \mathrm{L}$ & -0.060 & 0.469 \\
\hline Lactate dehydrogenase, $\mathrm{U} / \mathrm{L}$ & -0.292 & $<0.001$ \\
\hline C-reactive protein, $\mathrm{mg} / \mathrm{L}$ & -0.292 & $<0.001$ \\
\hline D dimer, ng/mL & -0.561 & $<0.001$ \\
\hline Ferritin, ng/mL & -0.594 & $<0.001$ \\
\hline Pulse oxygen saturation & 0.910 & $<0.001$ \\
\hline
\end{tabular}

By using linear regression analysis test, results showed that pulse oxygen saturation and $\mathrm{D}$ dimer were independently correlated with serum 25(OH)-D (Table 5).

Table (5): Linear regression analyses in COVID-19 patients to test the influences of the main independent variables against serum 25(OH)-D (ng/ml) levels (dependent variable)

\begin{tabular}{|c|c|c|c|c|c|c|c|}
\hline \multirow{2}{*}{ Model } & \multicolumn{2}{|c|}{$\begin{array}{l}\text { Unstandardized } \\
\text { Coefficients }\end{array}$} & \multirow{2}{*}{$\begin{array}{c}\begin{array}{c}\text { Standardized } \\
\text { Coefficients }\end{array} \\
\text { Beta }\end{array}$} & \multirow{2}{*}{$\mathbf{t}$} & \multirow{2}{*}{$\mathbf{P}$} & \multicolumn{2}{|c|}{ 95\% C.I } \\
\hline & B & SE & & & & $\begin{array}{l}\text { Lower } \\
\text { Bound }\end{array}$ & $\begin{array}{l}\text { Upper } \\
\text { Bound }\end{array}$ \\
\hline (Constant) & -18.664 & 1.790 & & -10.425 & $<0.001$ & -22.203 & -15.125 \\
\hline $\begin{array}{l}\text { Pulse oxygen } \\
\text { saturation }\end{array}$ & 0.390 & 0.020 & 1.150 & 19.866 & $<0.001$ & 0.351 & 0.429 \\
\hline Platelets, $\times 109 / \mathrm{L}$ & 0.001 & 0.0002 & 0.013 & 0.342 & 0.733 & -0.003 & 0.004 \\
\hline Lymphocytes $\times 109 / \mathrm{L}$ & -0.386 & 0.12 & -0.059 & -1.822 & 0.071 & -0.805 & 0.033 \\
\hline Ferritin, $\mathrm{ng} / \mathrm{mL}$ & 0.001 & 0.0001 & 0.050 & 1.156 & 0.250 & -0.001 & 0.004 \\
\hline D dimer, $\mathrm{ng} / \mathrm{mL}$ & 0.301 & 0.053 & 0.274 & 5.691 & $<0.001$ & 0.196 & 0.405 \\
\hline
\end{tabular}

The power of serum 25(OH)-D in differentiating severe and critical COVID-19 from mild and moderate cases at admission was demonstrated by receiver operating characteristic (ROC) analysis, the area under the curve (AUC) was $0.9(95 \% \mathrm{CI}=0.85-0.95)$ with sensitivity $=96.8 \%$, specificity $=68.1 \%$, and the cutoff value $(11.5 \mathrm{ng} / \mathrm{ml})($ Figure 2$)$. 


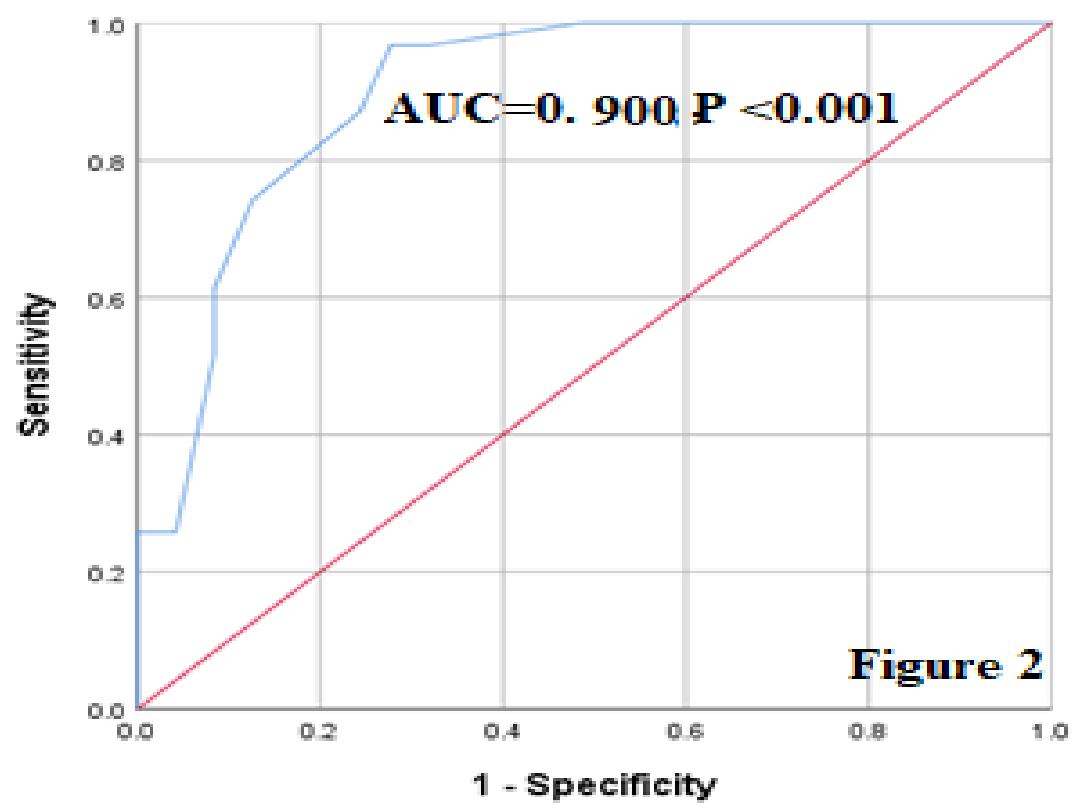

Figure (2): Receiver operating characteristic curve of the serum 25(OH)-D (ng/ml) in differentiating severe and critical COVID-19 from mild and moderate cases

\section{DISCUSSION}

Noticeably, it emerges that vitamin D deficiency is a major public health problem worldwide in all age groups ${ }^{(16,17)}$. However vitamin D deficiency is more prominent in the elderly, due to decreased cutaneous synthesis ${ }^{(18)}$. In addition, vitamin $\mathrm{D}$ deficiency is more observed in people with poor exposure to sunlight ${ }^{(\mathbf{1 9})}$.

Numerous evidence has shown a high prevalence of vitamin D deficiency in the critically ill patient population, with approximately $60 \%$ of patients found to be vitamin D deficient, (25(OH)-D concentrations $<20 \mathrm{ng} / \mathrm{mL}$ ), and an additional $30 \%$ of patients being vitamin $\mathrm{D}$ insufficient, $(25(\mathrm{OH})-\mathrm{D}=20$ $30 \mathrm{ng} / \mathrm{mL})^{(20)}$. Multiple studies have also confirmed that independent associations between low serum 25(OH)-D and susceptibility to acute respiratory tract infections ${ }^{(21)}$. There is some controversy regarding the contribution of serum $25(\mathrm{OH})$-D in the treatment or prevention of infection in particular COVID-19. Thus, the current research aimed to estimate the serum levels of 25(OH)-D in patients with COVID-19 infection in correlation to clinical manifestations and severity.

The main finding of the present study is that COVID -19 patients had lower values of serum 25(OH)D compared to normal levels. Interestingly, the levels of serum $25(\mathrm{OH})$-D were significantly low in severe and critical groups compared to mild and moderate groups.

Many different theories have been brought forth in an attempt to explain the mechanisms responsible for the increased severity of COVID-19. According to Cui $\boldsymbol{e}$ a $\boldsymbol{a l}^{\mathbf{( 2 2 )}}$ study, vitamin D receptor activation controls microglia polarization and oxidative stress in spontaneously hypertensive rats and angiotensin II-exposed microglial cells. Consequently, a hypothesis could be formulated that decreased vitamin $\mathrm{D}$ worsens the ability of macrophages to mature, to produce macrophage-specific surface antigens, to produce the lysosomal enzyme acid phosphatase, and to secrete $\mathrm{H}_{2} \mathrm{O}_{2}$, a function integral to their antimicrobial function ${ }^{(23)}$.

A similar finding was observed by D'avolio et al. ${ }^{(24)}$ as lower concentrations of circulating 25(OH)-D were also reported to be associated with susceptibility to SARS-CoV-2. Also, Panagiotou et al. ${ }^{(25)}$ found low serum 25(OH)-D levels in patients hospitalized with COVID-19 and associated with more disease severity of COVID-19.

In agreement with our study Han et al. ${ }^{(26)}$ pilot study detected that administration of high-dose vitamin D3 safely increased plasma 25(OH)-D concentrations into the sufficient range and was associated with decreased hospital length of stay without altering other clinical outcomes.

In a study conducted by Hastie $\boldsymbol{e t}$ al. ${ }^{(27)}$, the results are consistent with previous studies (12) in proving a higher risk of confirmed COVID-19 infection in ethnic minority groups. Even more importantly, Grant et al. ${ }^{(28)}$ investigated provided evidence that vitamin D supplementation could reduce the risk of influenza and COVID-19 infections and deaths. On the contrary, a study by Faul et $\boldsymbol{a l} .{ }^{(29)}$ noticed no association between 25(OH)-D and COVID-19 infection after adjusting for potential confounders.

The interesting result of our study was that there was a significant positive correlation between serum 25(OH)-D levels and hemoglobin, platelets, albumin, and $\mathrm{SPO}_{2}$ values. On the other hand, there was a significant negative correlation between serum 25(OH)-D levels and LDH, C-reactive protein, D dimer, and ferritin levels. 
Even more importantly, we further have evaluated the current study results by linear regression analysis test to estimate the most independent factors correlated with serum 25(OH)-D levels and we detected that $\mathrm{PSO}_{2}$ and $\mathrm{D}$ dimer were independently correlated with serum $25(\mathrm{OH})-\mathrm{D}$, at cutoff values $11.5 \mathrm{ng} / \mathrm{ml}$ serum $25(\mathrm{OH})$-D could differentiate severe and critical COVID -19 from mild and moderate cases by ROC analysis with sensitivity and specificity $(96.8 \%, 68.1 \%$, respectively.

Emerging evidence demonstrated that vitamin D deficiency has been linked to increased morbidity and mortality in COVID -19 infections ${ }^{(30)}$. Moreover, an interesting study found that each $4 \mathrm{ng} / \mathrm{mL}$ increase in circulating $25(\mathrm{OH})$-D levels was associated with a $7 \%$ decreased risk of seasonal infection, a decrement of approximately $1.75 \%$ per $\mathrm{ng} / \mathrm{mL}{ }^{(31)}$. Similar results were obtained by Harvey et al. ${ }^{(32)}$, they confirmed that COVID -19 infection is strongly and inversely correlated with circulating 25(OH)-D levels, a relationship that continues across latitudes, races/ethnicities, sexes, and age ranges.

Considering all the above, the current study findings offer further rationale to explore the role of vitamin D supplementation especially in patients with insufficient levels in reducing COVID-19 severity, hospitalizations, and morbidity disease and we recommended further double-blind controlled clinical trials to evaluate the impact of vitamin D supplementation on COVID-19 severity and mortality in particular patients with vitamin D deficiency. This could be of increased importance for poor or lowincome communities, who are disproportionately affected by both COVID-19 and vitamin D deficiency. In this respect, we recommend responsible vitamin D supplementation based on personal needs, risk factors, and advice from personal physicians in accordance with existing Endocrine Society Guidelines ${ }^{(33)}$.

\section{CONCLUSIONS}

Patients with COVID-19; in particular patients with severe and critical COVID-19 had a significantly low level of serum 25(OH)-D compared to mild and moderate cases, in addition, $\mathrm{PSO}_{2}$ and $\mathrm{D}$ dimer were independently correlated with serum $25(\mathrm{OH})$-D. Thus, low serum $25(\mathrm{OH})-\mathrm{D}$ level could be a predictor of severe and critical COVID - 19.

Financial support and sponsorship: Nil. Conflict of Interest: Nil.

\section{REFERENCES}

1. Ackermann M, Verleden S, Kuehnel M (2020): Pulmonary vascular endothelialitis, thrombosis, and angiogenesis in COVID-19. The New England Journal of Medicine, 383(2):120-128.

2. Alonso-Fernández A, Toledo-Pons N, Cosío B (2020): Prevalence of pulmonary embolism in patients with COVID-19 pneumonia and high D-dimer values: A prospective study. doi: 10.1371/journal.pone.0238216.
3. Ameri P, Inciardi $R$, Di Pasquale M (2020): Pulmonary embolism in patients with COVID-19: characteristics and outcomes in the Cardio-COVID Italy multicenter study. Clinical Research in Cardiology, 3:19.

4. Artifoni M, Danic G, Gautier G (2020): Systematic assessment of venous thromboembolism in COVID-19 patients receiving thromboprophylaxis: incidence and role of D-dimer as predictive factors. Journal of Thrombosis and Thrombolysis, 50(1):211-216.

5. Liu P, Stenger S, Li H et al. (2006): Toll-like receptor triggering of a vitamin D-mediated human antimicrobial response. Science, 311(5768):1770-3.

6. Chen S, Sims G, Chen X et al. (2007): Modulatory effects of 1,25-dihydroxyvitamin D3 on human B cell differentiation. J Immunol., 179(3):1634-47.

7. Boonstra A, Barrat F, Crain C et al. (2001): 1alpha,25Dihydroxyvitamin $\mathrm{d} 3$ has a direct effect on naive CD4(+) $\mathrm{T}$ cells to enhance the development of Th2 cells. J Immunol., 167(9):4974-80.

8. Tang J, Zhou R, Luger D et al. (2009): Calcitriol suppresses antiretinal autoimmunity through inhibitory effects on the Th17effector response. J Immunol., 182(8):4624-32.

9. Gorman S, Kuritzky L, Judge M et al. (2007): Topically applied 1,25-dihydroxyvitamin D3 enhances the suppressive activity of $\mathrm{CD} 4+\mathrm{CD} 25+$ cells in the draining lymph nodes. J Immunol., 179(9):6273-83.

10. Teymoori-Rad M, Shokri F, Salimi V et al. (2019): The interplay between vitamin D and viral infections. Rev Med Virol., 29: 2032-36.

11. Guo $Y$, Cao $Q$, Hong $Z$ et al. (2020): The origin, transmission and clinical therapies on coronavirus disease 2019 (COVID-19) outbreak - an update on the status. Military Med Res., 7:11-16.

12. Jakovac H (2020): COVID-19 and vitamin D-is there a link and an opportunity for intervention? Am J Physiol Endocrinol Metab., 318: 589-93.

13. Xiao F, Tang $M$, Zheng $X$ et al. (2020): Evidence for gastrointestinal infection of SARS-Cov-2. Gastroenterology, 158(6):1831-1833.

14. WHO (2020): Clinical management of severe acute respiratory infection (SARI) when COVID-19 disease is suspected: Interim Guidance, 13 March 2020. https://apps.who.int/iris/handle/10665/331446

15. Holick M (2007): Vitamin D deficiency. N Engl J Med., 357:266-281.

16. Palacios C, Gonzalez L (2014): Is vitamin D deficiency a major global public health problem? J Steroid Biochem Mol Biol., 144:138-145.

17. MacLaughlin J, Holick M (1985): Aging decreases the capacity of human skin to produce vitamin D3. J Clin Investig., 76:1536-1538.

18. Adami S, Bertoldo F, Braga $V$ et al. (2009): 25Hydroxy vitamin D levels in healthy premenopausal women: association with bone turnover markers and bone mineral density. Bone, 45:423-426.

19. Lips P, Cashman K, Lamberg-Allardt C et al. (2019): Current vitamin D status in European and Middle East countries and strategies to prevent vitamin D deficiency: a position statement of the European Calcified Tissue Society. Eur J Endocrinol., 180:23-54.

20. Jeng L, Yamshchikov A, Judd S et al. (2009): Alterations in vitamin D status and anti-microbial 
peptide levels in patients in the intensive care unit with sepsis. J Transl Med., 7:28-33.

21. Cannell J, Vieth R, Umhau J et al. (2006): Epidemic influenza and vitamin D. Epidemiol Infect., 356:11291140.

22. Cui C, Xu P, Li G et al. (2019): Vitamin D receptor activation regulates microglia polarization and oxidative stress in spontaneously hypertensive rats and angiotensin II-exposed microglial cells: Role of renin-angiotensin system. Redox Biol., 26:101295.

23. Abu-Amer Y, Bar-Shavit $Z$ (1993): Impaired bone marrow-derived macrophage differentiation in vitamin D deficiency. Cell Immunol., 151:356-368.

24. D'Avolio A, Avataneo V, Manca A et al. (2020): 25hydroxyvitamin D concentrations are lower in patients with positive PCR for SARS-CoV-2. Nutrients, 12(5):1359.

25. Panagiotou G, Tee $S$, Ihsan Y et al. (2020): Low serum 25-hydroxyvitamin D $(25(\mathrm{OH}) \mathrm{D})$ levels in patients hospitalised with COVID-19 are associated with greater disease severity. Clin Endocrinol (Oxf), 93(4):508-511.

26. Han J, Jones J, Tangpricha $\mathbf{V}$ et al. (2016): High dose vitamin $\mathrm{D}$ administration in ventilated intensive care unit patients: a pilot double blind randomized controlled trial. J Clin Transl Endocrinol., 4:59-65.
27. Hastie C, Mackay D, Ho F et al. (2020): Vitamin D concentrations and COVID-19 infection in UK Biobank. Diabetes Metab., 14(4):561-5.

28. Grant W, Lahore H, McDonnell S et al. (2020): Evidence that vitamin D supplementation could reduce risk of influenza and COVID-19 infections and deaths. Nutrients, 12(4):988-994.

29. Faul J, Kerley C, Love B et al. (2020): Vitamin D deficiency and ARDS after SARS-CoV-2 infection. Ir Med J., 113:84-88.

30. Singh S, Rujul J, Shipra S (2020): Vitamin D deficiency in patients with diabetes and COVID- 19 infection. Diabetes \& Metabolic Syndrome, 14(5): 1033 1035.

31. Berry D, Hesketh K, Power C et al. (2011): Vitamin D status has a linear association with seasonal infections and lung function in British adults. $\mathrm{Br} \mathrm{J}$ Nutr., 106(9):1433-40.

32. Harvey W, Justin $K$, Martin $H$ et al. (2020): SARSCoV-2 positivity rates associated with circulating 25hydroxyvitamin D levels. DOI:10.1371/journal.pone.0239252

33. Holick M, Binkley N, Bischoff-Ferrari H et al. (2011): Evaluation, treatment and prevention of vitamin D deficiency: An Endocrine Society Clinical Practice Guideline. J Clin Endocrinol Metab., 96(7):1911-1930. 